\title{
Silencing TGIF suppresses migration, invasion and metastasis of MDA-MB-231 human breast cancer cells
}

\author{
YADONG WANG ${ }^{1,2}$, LI LI $^{1}$, HAIYU WANG ${ }^{1}$, JIANGMIN LI $^{1}$ and HAIYAN YANG ${ }^{3}$ \\ ${ }^{1}$ Department of Toxicology, Henan Center for Disease Control and Prevention, Zhengzhou, Henan 450016; \\ ${ }^{2}$ Henan Collaborative Innovation Center of Molecular Diagnosis and Laboratory Medicine, Xinxiang Medical University, \\ Xinxiang, Henan 453003; ${ }^{3}$ Department of Epidemiology, School of Public Health, \\ Zhengzhou University, Zhengzhou, Henan 450001, P.R. China
}

Received June 12, 2017; Accepted November 29, 2017

DOI: $10.3892 /$ or.2017.6133

\begin{abstract}
This study explored the potential role of TG-interacting factor (TGIF) in migration, invasion and metastasis of the human breast cancer cell line MDA-MB-231. Western blot assay, immunohistochemistry and qRT-PCR assays were applied to detect the expression of protein and mRNA. Wound healing assay, Transwell invasion assay and tail vein metastatic assay were performed to assess the migration, invasion and metastasis of stable TGIF-silenced MDA-MB-231 cell line in vitro and in vivo. The significantly higher frequency of TGIF high-expression was observed in metastatic breast cancer $(62.9 \%)$ compared to that in nonmetastatic breast cancer (25.8\%). Silencing TGIF suppressed migration and invasion of MDA-MB-231 cells in vitro and tumor metastasis in nude mouse models. The expression of Snail1, matrix metalloproteinase 2 (MMP2) and $\beta$-catenin was markedly decreased in the stable TGIF-silenced MDA-MB-231 cells compared with the control cells. Our results suggest that silencing TGIF suppressed the migration, invasion and metastasis of the human breast cancer cell line MDA-MB-231 using in vitro and in vivo experiments.
\end{abstract}

\section{Introduction}

Breast cancer is the most commonly diagnosed cancer and the first leading cause of cancer-related death among women worldwide, with an estimated 1.7 million cases and 521,900 deaths in 2012. Breast cancer alone accounts for

Correspondence to: Dr Yadong Wang, Department of Toxicology, Henan Center for Disease Control and Prevention, 105 South Nongye Road, Zhengzhou, Henan 450016, P.R. China

E-mail: wangyd76@163.com

Dr Haiyan Yang, Department of Epidemiology, School of Public Health, Zhengzhou University, 100 Science Road, Zhengzhou, Henan 450001, P.R. China

E-mail: yhy@zzu.edu.cn

Key words: TGIF, migration, invasion, metastasis, MDA-MB-231, breast cancer
$25 \%$ of all cancer cases and $15 \%$ of all cancer-related deaths among women (1). The main reason for breast cancer-related deaths is tumor metastasis. Thus, it is of great significance that much effort should be paid to fully understand the mechanism of breast cancer metastasis and to establish an effective method to inhibit tumor metastasis.

TG-interacting factor (TGIF) is a transcriptional repressor, which is involved in the signaling pathways of retinoic acid (RA) and transforming growth factor $\beta$ (TGF- $\beta)(2,3)$. Increasing evidence suggests that TGIF is associated to the initiation, development and progression of several kinds of tumors, including leukemia $(4,5)$, esophageal carcinoma and gastric carcinoma $(6,7)$, hepatocellular carcinoma (8), lung cancer $(9,10)$ and upper tract urothelial carcinoma $(11,12)$. Recently, Zhang et al reported that TGIF drove mammary tumorigenesis and the elevated TGIF expression was correlated with high Wnt signaling and poor survival of triple-negative breast cancer (TNBC) patients (13). Kwon et al reported that targeted interference of SIN3A-TGIF function by SID decoy treatment inhibits Wnt signaling and the abilities of invasion in TNBC cells (14). However, it is not fully clear what the potential function of TGIF is in the metastasis of human breast cancer.

To address the potential function of TGIF in the metastasis of human breast cancer, we explored the effects of silencing TGIF on the migration, invasion and metastasis of the human breast cancer cell line of MDA-MB-231 using in vitro and in vivo experiments in the present study. We also investigated the pattern of TGIF protein expression in metastatic human breast cancer samples and non-metastatic human breast cancer samples.

\section{Materials and methods}

Cell culture. MDA-MB-231 cell line was obtained from the Cell Resource Center, Peking Union Medical College (which is the headquarters of National Infrastructure of Cell Line Resource, NSTI) and was cultured in DMEM supplemented with $2 \mathrm{mM}$ of L-glutamine, $10 \%$ of fetal bovine serum (FBS), streptomycin $(100 \mu \mathrm{g} / \mathrm{ml})$ and penicillin $(100 \mathrm{U} / \mathrm{ml})$ at $37^{\circ} \mathrm{C}$ in a humidified atmosphere containing $5 \% \mathrm{CO}_{2}$. For infection, control shRNA lentiviral particles-A (sc-108080) and 
TGIF shRNA (h) lentiviral particles (sc-36659-V) were purchased from Santa Cruz Biotechnology, Inc. (Dallas, TX, USA). MDA-MB-231 cells were infected with lentiviral particles in accordance with the manufacturer's instructions and were selected with $10 \mu \mathrm{g} / \mathrm{ml}$ of puromycin for 28 days (Gibco; Thermo Fisher Scientific, Inc., Waltham, MA, USA). MDA-MB-231 cells that were successfully infected with control shRNA lentiviral particles and TGIF shRNA (h) lentiviral particles were termed MDA-MB-231-control-shRNA cell and MDA-MB-231-TGIF-shRNA cell, respectively.

Biological samples. Sixty-six breast cancer tissue samples were collected at the First Affiliated Hospital of Zhengzhou University from October 2013 to December 2014. Written informed consent was obtained from individual patients. The Ethics Committee of the First Affiliated Hospital of Zhengzhou University approved this study.

Measurement of cell proliferation. MDA-MB-231-TGIFshRNA cells $\left(4 \times 10^{4}\right)$ and MDA-MB-231-control-shRNA cells were seeded in 12-well plates. Cells were counted using a CASY Cell Counter (Scharfe System, Germany) at 24, 48, 72 and 96 h, respectively (15).

Wound healing assay. The wound healing assay was performed according to our previous report (16). Cells were wounded by scratching the surface of a 6-well plate with a $200-\mu 1$ pipette tip. Floating cells were removed through washing with PBS. The cells were maintained at $37^{\circ} \mathrm{C}$ for $48 \mathrm{~h}$. The photographic images were taken by using a Leica DM IL LED inverted microscope at different time-points. The healing width was calculated according to our previous report (16).

Transwell invasion assay. The cell invasion assay was performed in accordance with the manufacturer's instructions (Corning Inc., Corning, NY, USA). MDA-MB-231-TGIF-shRNA cells $\left(5 \times 10^{4}\right)$ and MDA-MB-231-control-shRNA cells were plated into the upper chamber of a 24-well Transwell chamber with an $8-\mu \mathrm{m}$ pore size insert (Corning Inc.) with Matrigel (BD Biosciences, Franklin Lakes, NJ, USA). The lower chambers were filled with $600 \mu \mathrm{l}$ of DMEM containing $10 \%$ FBS. After $24 \mathrm{~h}$ of incubation at $37^{\circ} \mathrm{C}$, the cells on the upper side of the membrane were removed, and the membranes were fixed in methanol and stained with crystal violent (Sigma-Aldrich, St. Louis, MO, USA). The cells on the lower surfaces were photographed and five randomly selected fields were counted (16).

Tail vein metastatic assay. The Ethics Committee of Henan Center for Disease Control and Prevention approved this study. All of the animal experiments were conducted in accordance with the guidelines for the Care and Use of Laboratory Animals. Female BALB/c nude mice aged 28 days were purchased from Vital River Laboratory Animal Technology Co., Ltd. (Beijing, China). MDA-MB-231-TGIF-shRNA cells and MDA-MB-231-control-shRNA cells were detached by trypsinization, washed with PBS, and then re-suspended in PBS. Cells $\left(6 \times 10^{5}\right)$ in $200 \mu$ PBS were injected to each mouse (ten mice per group) by tail vein. The mice were sacrificed at 12 weeks post-injection. The lungs were examined for tumor metastasis $(17,18)$.
Quantitative real-time polymerase chain reaction ( $q R T-P C R)$. The detailed methods of total RNA extraction, cDNA synthesis and quantitative real-time PCR were performed as previously described (9).

Western blot assay. Soluble cell lysates (30 $\mu \mathrm{g}$ protein) were loaded and separated in 10\% SDS-PAGE gel. Proteins were transferred to nitrocellulose (NC) membranes (Pall Life Sciences, Port Washington, NY, USA). The membranes were blocked with $5 \%$ bovine serum albumin (BSA), and then incubated with primary antibodies overnight at $4^{\circ} \mathrm{C}$. TGIF (sc-9084), MMP2 (sc-10736), N-cadherin (sc-7939), $\beta$-catenin (sc-7199) and $\beta$-actin (sc-8432) were purchased from Santa Cruz Biotechnology Inc. Snail1 (\#3879S) and vimentin (\#5741S) were purchased from Cell Signaling Technology. The membranes were washed with Tris-buffered salineTween-20 (TBST) and further incubated for $1 \mathrm{~h}$ at room temperature with corresponding horseradish peroxidasecoupled secondary antibodies (ZSGB-BIO, Beijing, China). Signals were detected by ECL kit (Bio-Rad, Hercules, CA, USA).

Immunohistochemistry. Immunohistochemistry analysis was performed according to the manufacturer's instructions (CW2069; Beijing ComWin Biotech Co., Ltd). The primary antibody of TGIF (sc-17800) was obtained from Santa Cruz Biotechnology. The intensity of TGIF staining was scored and the scores of positive cell percentage were assigned in line with a published report (19).

Statistical analysis. SPSS 13.0 software (SPSS, Inc., Chicago, IL, USA) was used to estimate the statistical significance. Student's t-test and Chi-square were performed. P-value $<0.05$ was considered to indicate statistical significance.

\section{Results}

The effects of silencing TGIF on MDA-MB-231 cell proliferation. Fig. 1 presented the silencing efficiency of the shRNA lentiviruses by determining the levels of mRNA and protein expression in the MDA-MB-231 human breast cancer cells. Our data indicated that the lower levels of protein (Fig. 1A) and mRNA (Fig. 1B) of TGIF expression were observed in MDA-MB-231-TGIF-shRNA cells compared to that in MDA-MB-231-control-shRNA cells, suggesting that a stable TGIF-silenced MDA-MB-231 cell line was successfully established.

Fig. 1C demonstrates the effects of silencing TGIF on the proliferation of MDA-MB-231 cells. Our results showed that no significant difference was observed in the cell growth speed between the MDA-MB-231-TGIF-shRNA cells and the MDA-MB-231-control-shRNA cells at the indicated time-points.

The effects of silencing TGIF on the migration and invasion of $M D A-M B-231$ cells. Data on the effects of silencing TGIF on migration and invasion of MDA-MB-231 cells are presented in Fig. 2. Our results indicated that the MDA-MB-231-TGIFshRNA cells migrated less quickly to close the scratched wounds than the MDA-MB-231-control-shRNA cells (Fig. 2A). Fig. 2B 
A
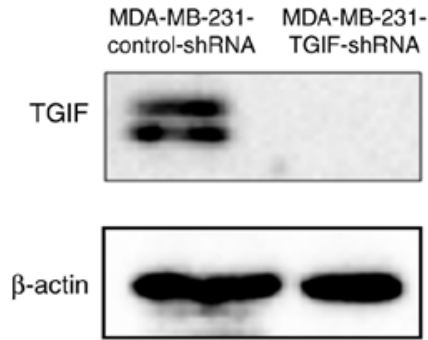

B

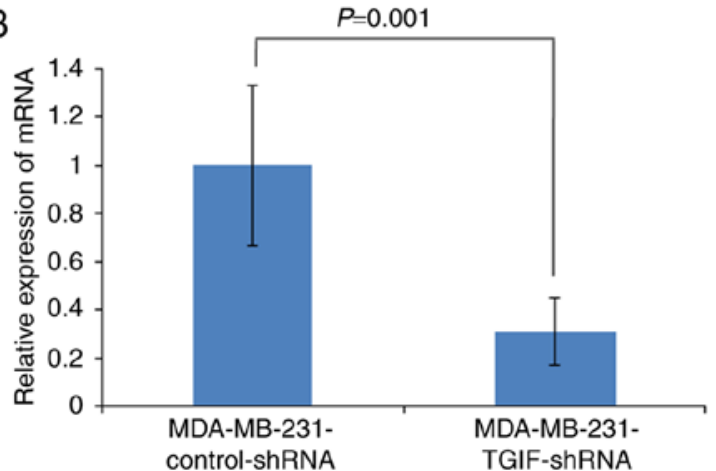

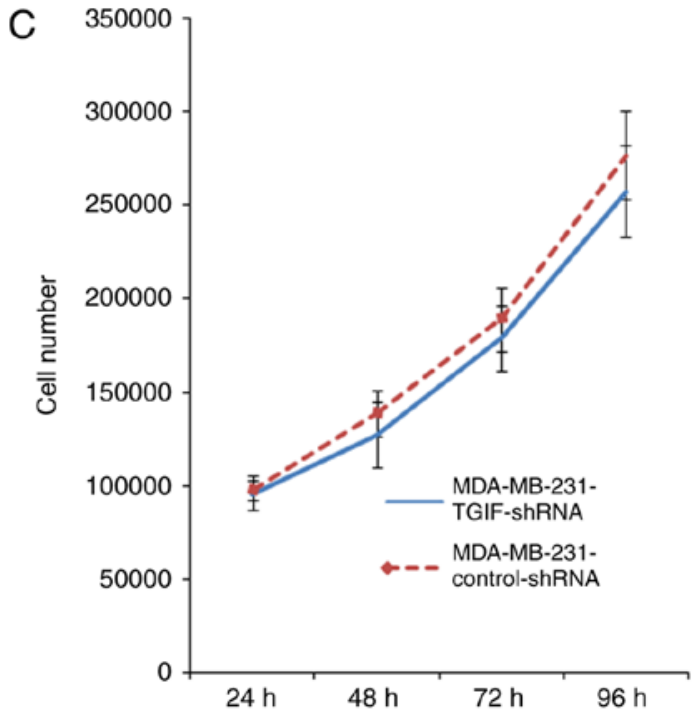

Figure 1. The silencing efficiency of shRNA targeting TGIF in MDA-MB-231 cells and the effects of silencing TGIF on MDA-MB-231 cell proliferation. (A) Western blot analysis indicated that shRNA specifically targeting TGIF markedly decreased the level of TGIF protein expression in MDA-MB-231 cells. (B) qRT-PCR analysis also indicated that shRNA specifically targeting TGIF markedly decreased the level of TGIF mRNA expression in MDA-MB-231 cells. (C) Silencing TGIF had no significant effects on the proliferation of MDA-MB-231 cells. TGIF, TG-interacting factor. qRT-PCR, quantitative real-time polymerase chain reaction (qRT-PCR)

A
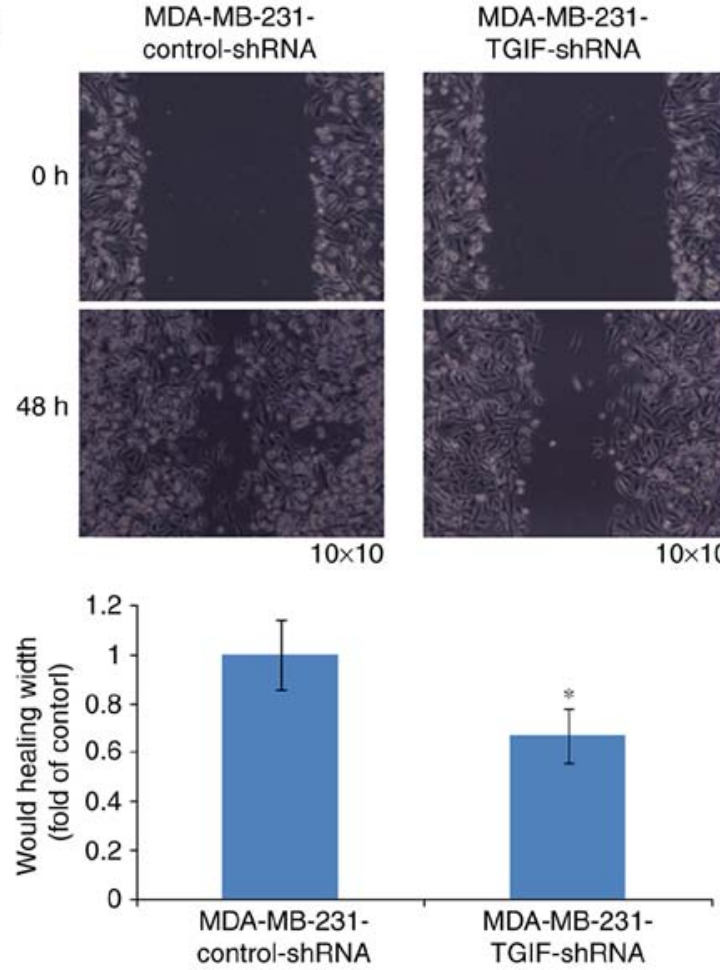

B
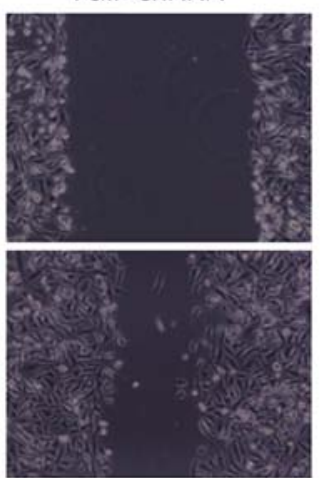

$10 \times 10$

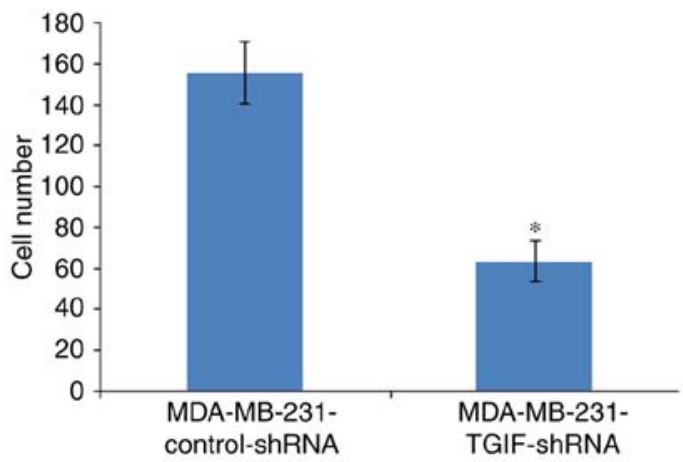

Figure 2. The effects of silencing TGIF on the migration and invasion of MDA-MB-231 cells. The cells migrated less quickly to close the scratched wounds in MDA-MB-231-TGIF-shRNA cells as compared to MDA-MB-231-control-shRNA cells (A). The significantly decreased number of cells invading through the Matrigel was observed in MDA-MB-231-TGIF-shRNA cells as compared to MDA-MB-231-control-shRNA cells (B). "P<0.05. TGIF, TG-interacting factor.

showed that the decreased number of cells invading through the Matrigel was observed in the MDA-MB-231-TGIF-shRNA cells compared with the MDA-MB-231-control-shRNA cells.
Taken together, our findings suggested that silencing TGIF was able to inhibit migration and invasion of human breast cancer cell line of MDA-MB-231 in in vitro experiments. 
A

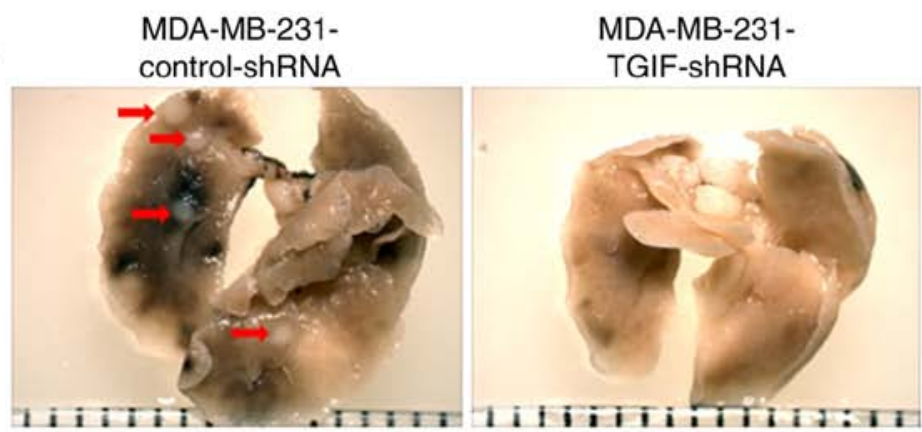

B

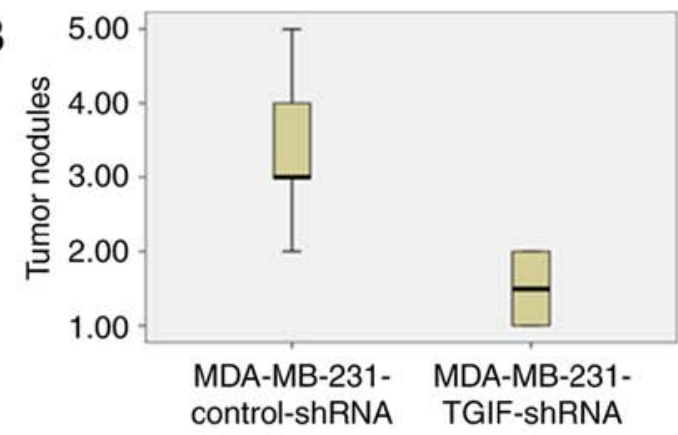

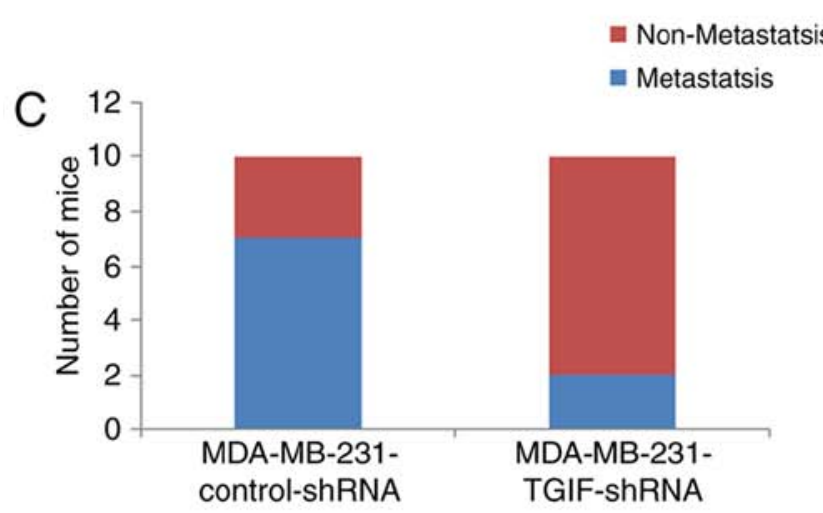

D

MDA-MB-231control-shRNA

d- 1
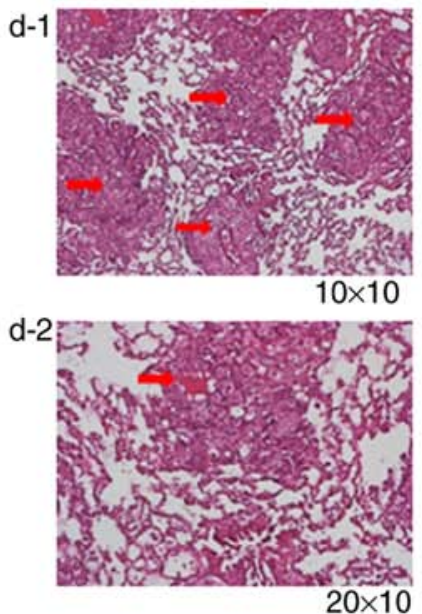

MDA-MB-231-

TGIF-shRNA
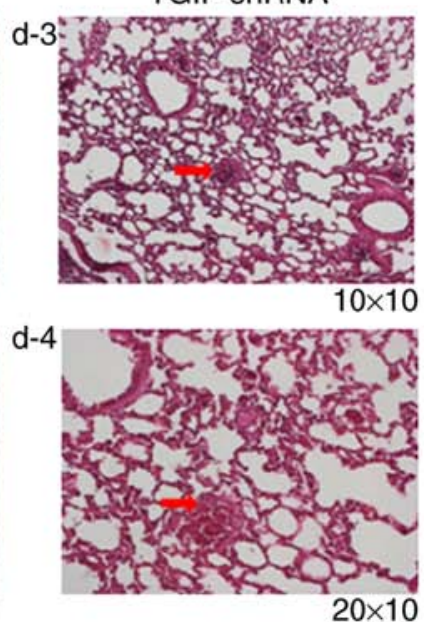

Figure 3. The effects of silencing TGIF on the ability of the metastasis of MDA-MB-231 cells in vivo. (A) The representative images of tumor nodules of lung surface are indicated. The number of metastatic lung nodules was significantly reduced in MDA-MB-231-TGIF-shRNA group as compared to the control group (B). The incidence rate of metastasis in mouse lung was lower in MDA-MB-231-TGIF-shRNA group than that in the control group (C). (D) The representative images of histological examinations are shown. The red arrows indicated the tumor nodules. TGIF, TG-interacting factor.

The effects of silencing TGIF on MDA-MB-231 cell metastasis in vivo. Fig. 3 shows the effects of silencing TGIF on MDA-MB-231 cell metastasis in vivo. The representative images of tumor nodules are demonstrated in Fig. 3A. Our data indicated that the significantly reduced number of metastatic lung nodules was observed in the group of MDA-MB-231-TGIF-shRNA cells compared with the control group (Fig. 3B). The mice injected with MDA-MB-231-TGIF-shRNA cells had markedly decreased incidence of lung metastasis compared with those injected with MDA-MB-231-control-shRNA cells ( $\mathrm{P}=0.029$; Fig. 3C). The representative images of histological examinations are shown in Fig. 3D.

Silencing TGIF downregulates the expression of Snaill, MMP2 and $\beta$-catenin. Since the proteins such as MMP2, Snail1, N-cadherin, vimentin and $\beta$-catenin are involved in the progression and metastasis of human breast cancer (20-24), we tentatively sought to observe whether silencing TGIF could affect the protein expression of Snail1, MMP2, N-cadherin, vimentin and $\beta$-catenin. Western blot analysis indicated that the obviously decreased levels of Snail1, MMP2 and $\beta$-catenin protein expression were observed in MDA-MB-231-TGIFshRNA cells compared with MDA-MB-231-control-shRNA cells (Fig. 4).
Table I. The main clinical characteristics of human breast cancer.

\begin{tabular}{lc}
\hline & No. \\
\hline Age (years) & \\
$\leq 45$ & 22 \\
$>45$ & 44 \\
Histology type & \\
Ductal carcinoma & 11 \\
Invasive carcinoma & 55 \\
TNM stage & \\
I & 11 \\
II & 40 \\
III & 15 \\
Metastasis & \\
Yes & 35 \\
No & 31 \\
\hline
\end{tabular}

TGIF expression in human breast cancer tissues. The main clinical characteristics of human breast cancer patients are listed in Table I. Fig. 5 demonstrates the difference of TGIF expression between metastatic human breast cancer samples 


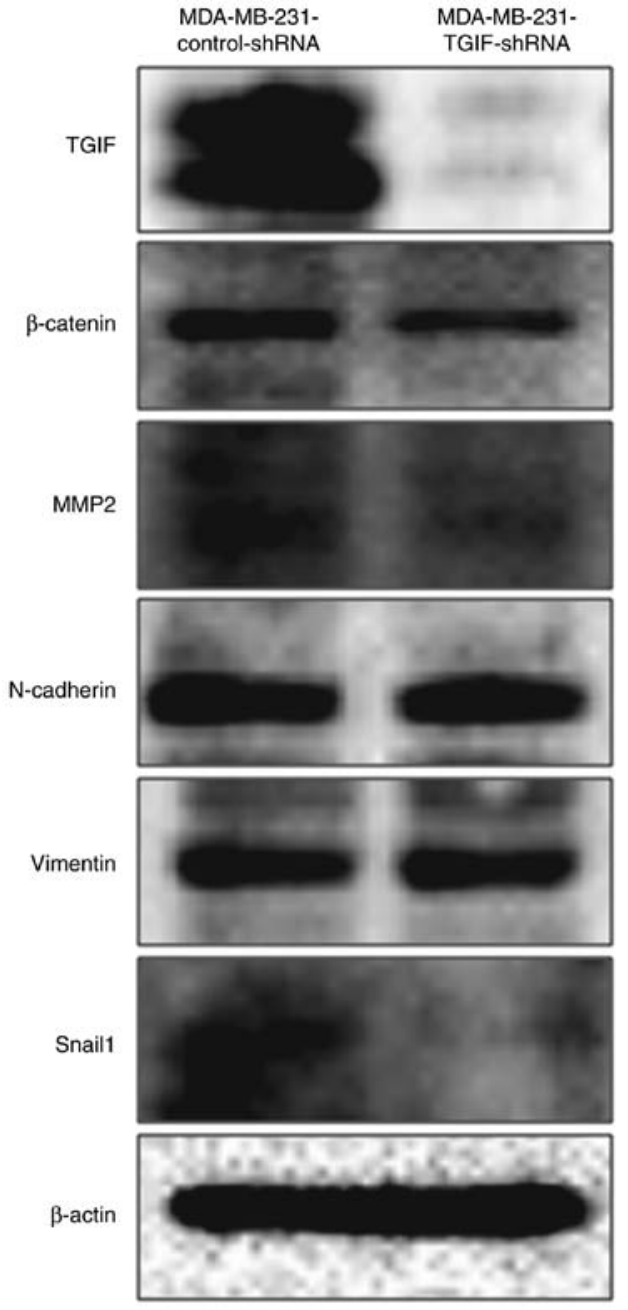

Figure 4. The effects of silencing TGIF on the expression of the studied proteins. Western blot analysis showed that silencing TGIF decreased the protein expression of Snail1, MMP2 and $\beta$-catenin. TGIF, TG-interacting factor. and non-metastatic human breast cancer samples. The representative images of TGIF low-expression (a-1, 10x10; a-2, 10x20) and TGIF high-expression (a-3, 10x10; a-4, 10x20) are shown in Fig. 5A. Our results indicated that the significantly higher percentage of TGIF high-expression was observed in metastatic human breast cancer $(62.9 \%, 22$ of 35$)$ than that in non-metastatic human breast cancer $(25.8 \%, 8$ of 31$)(\mathrm{P}=0.003$, Fig. 5B).

\section{Discussion}

To our knowledge, previous studies have shown that overexpression of TGIF is correlated to metastasis and worse progression in non-small cell lung cancer (NSCLC) (10) and upper urinary tract urothelial carcinoma $(11,12)$. Xiang et al reported that overexpression of TGIF increased the ability of migration of NSCLC cells, while suppressing TGIF expression inhibited the ability of migration of NSCLC cells. Moreover, knocking down TGIF impaired metastasis of NSCLC cells (10). Yeh et al reported that overexpression of TGIF could significantly increase the capabilities of migration and invasion of RT4 cells and TSGH8301 cells, on the contrary, knocking down TGIF inhibited the ability of invasion of T24 cells (11).

In this study, we investigated the effects of silencing TGIF on the migration and invasion of the human breast cancer cell line MDA-MB-231 in vitro. Our findings indicated that silencing TGIF inhibited the migration and invasion of MDA-MB-231 cells in wound healing assay and Transwell invasion assay, which suggested that TGIF might be involved in the metastasis of human breast cancer. Our results are consistent with data of a previous report, Kwon et al reported that a marked $80 \%$ reduction of cell invasion was observed in MDA-MB-231-luc-D3H2LN cells transfected with TGIFtargeting siRNA, compared with control cells (14). Our

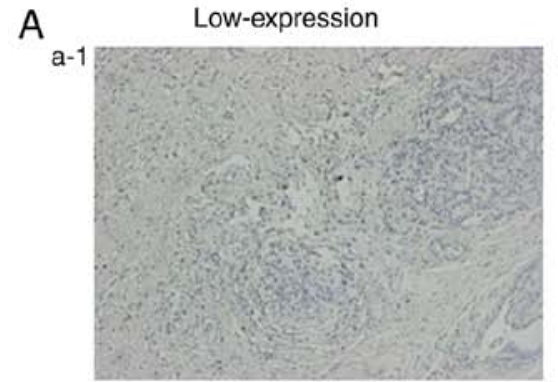

$10 \times 10$

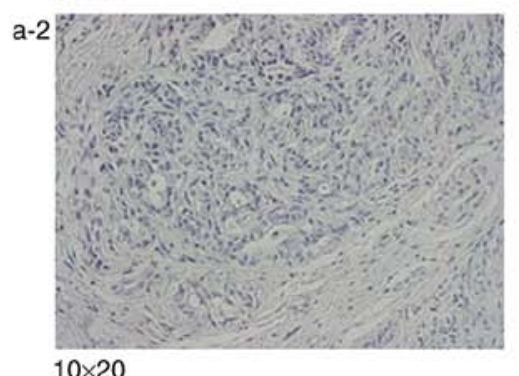

$10 \times 20$

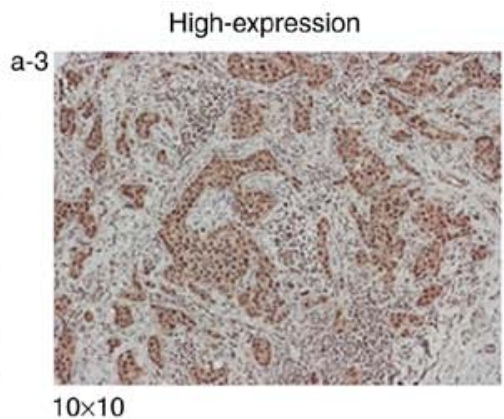

$10 \times 10$

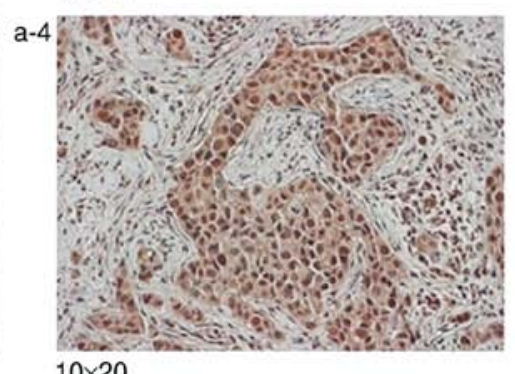

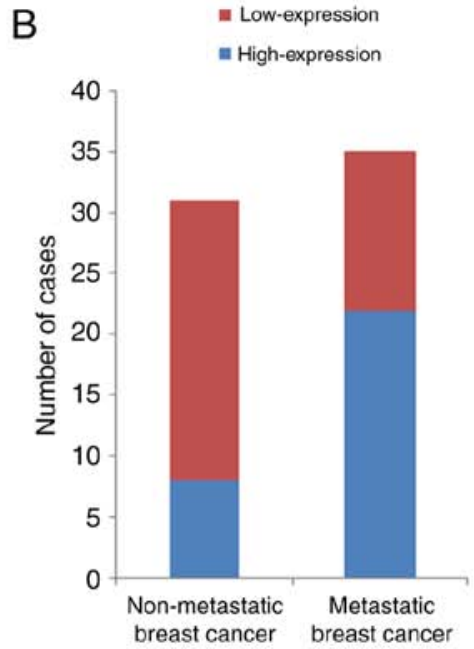

B

breast cancer breast cancer

Figure 5. The expression of TGIF in human breast cancer tissues detected by immunohistochemistry. The representative images showed low-expression (a-1, 10x10; a-2, 10x20) and high-expression (a-3, 10x10; a-4, 10x20) of TGIF in human breast cancer tissues (A). The higher percentage of TGIF highexpression was observed in metastatic human breast cancer than that in non-metastatic human breast cancer (B). TGIF, TG-interacting factor. 
findings also indicated that silencing TGIF inhibited metastasis of MDA-MB-231 cells to lung in vivo, which verified the potential role of TGIF in the metastasis of breast cancer in the animal model. Furthermore, we observed the rate of TGIF high-expression in metastatic human breast cancer samples was significantly higher than that in non-metastatic human breast cancer samples, which supported the notion that TGIF was involved in breast cancer metastasis in the population level.

In the present study, we observed that silencing TGIF reduced the MMP2 protein expression in the human breast cancer cell line MDA-MB-231. Previous reports suggested that TGIF could regulate the MMP2 expression in urothelial carcinoma cell lines $(11,12)$. Together, these studies supported that TGIF could regulate the MMP2 expression in different types of cell lines. MMP2 is one of the matrix-degrading enzymes, which plays a key role in the invasion and metastasis of breast cancer $(25,26)$. Published reports showed that the elevated MMP2 expression was related to poor prognostic clinical pathological factors in breast cancer (25,27-29). Pei et al reported that plantamajoside (PMS) inhibited the metastasis of breast cancer by decreasing the activity of MMP2 (30). $\mathrm{Ni}$ et al reported that downregulation of miR-106b induced breast cancer cell invasion and motility in association with overexpression of MMP2 (31). Accompanied with previous studies, our data suggested that TGIF silencing might inhibit metastasis of breast cancer via regulating MMP2. However, the underlying molecular mechanism should be explored in detail in future studies.

Snaill is a zinc-finger transcription factor, which plays a significant role in the progression and metastasis of breast cancer $(32,33)$. Moody et al reported that the higher levels of Snaill expression predicted decreased relapse-free survival of breast cancer patients and Snaill was sufficient to promote mammary tumor recurrence in vivo (34). Geradts et al reported that nuclear Snaill expression in early stage breast lesions might predict future development of invasive breast cancer (35). Results from Tran et al study showed that Snail1 expression in primary human breast cancer correlated with higher rates of metastasis (36). Zhang et al found the collagen receptor discoidin domain receptor 2 stabilized Snaill protein to promote the metastasis of human breast cancer (37). Tran et al reported that transient overexpression of Snail1 in primary breast tumors increased breast cancer metastasis in MMTV-NeuNT mice (38). In this study, we observed that silencing TGIF repressed Snaill protein expression in the human breast cancer cell line of MDA-MB-231, which suggested that the reduced abilities of the migration and invasion of human breast cancer cell line of MDA-MB-231 induced by silencing TGIF might be through partially downregulating Snaill protein expression. The inference should be verified in further studies through constructing TGIF-overexpressed and Snail-silenced cell models. Xiang et al observed that silencing TGIF reduced Snaill expression in NSCLC cells (10). However, the molecular mechanism of TGIF regulating the expression of Snaill was not addressed in this study, which should be a focus of future study.

$\beta$-catenin plays a significant role as a key mediator in the Wnt/ $\beta$-catenin signaling pathway, which is involved in the progression and metastasis of human breast cancer $(22,39,40)$ and modulates the sensitivity of breast cancer to ionizing radiation (41). Li et al reported that aberrant $\beta$-catenin expression was related to a poor clinical outcome in invasive human breast cancer (42). Lin et al reported that the elevated activity of $\beta$-catenin was significantly associated with poor prognosis of the breast cancer patients and was an independent prognostic factor (43). The higher levels of $\beta$-catenin expression had a significantly decreased overall survival of breast cancer patients (44). SiRNA-medicated decrease in the levels of $\beta$-catenin protein expression resulted in a significant inhibition of migration and invasion in the MDA-MB-231 cells (39). Stably knocking down $\beta$-catenin significantly suppressed the ability of migration of breast cancer cells compared to its corresponding control cells (45). In this study, silencing TGIF repressed the expression of $\beta$-catenin protein in the human breast cancer cell line MDA-MB-231, which suggested that TGIF silencing might suppress cell migration and invasion of breast cancer partially by repressing $\mathrm{Wnt} / \beta$-catenin signaling pathway. Two previous reports indicated that TGIF regulated the $\beta$-catenin expression in NSCLC cells and breast cancer cells $(10,13)$. The molecular mechanism of TGIF regulating the expression of $\beta$-catenin was reported showing TGIF was associated with and diverted Axin 1 and Axin 2 from the $\beta$-catenin destruction complex, therefore allowing $\beta$-catenin accrual (13). Together, these studies verified the regulation of $\beta$-catenin expression by TGIF.

In conclusion, our results suggest that silencing TGIF inhibited migration, invasion and metastasis of the human breast cancer cell line of MDA-MB-231 in vitro and in vivo. Therefore, this study extends our knowledge of the progression of breast cancer and suggests that TGIF might be a potential therapeutic target for human breast cancer.

\section{Acknowledgements}

This study was supported by grants from the National Natural Science Foundation of China (U1404815) and the Henan Collaborative Innovation Center of Molecular Diagnosis and Laboratory Medicine (XTCX-2015-PY7). The authors greatly thank Dr Wenlong Zhai and Dr Zhe Fu (Department of General Surgery, the First Affiliated Hospital of Zhengzhou University, Zhengzhou, China) for collecting the human breast cancer samples.

\section{References}

1. Torre LA, Bray F, Siegel RL, Ferlay J, Lortet-Tieulent J and Jemal A: Global cancer statistics, 2012. CA Cancer J Clin 65: 87-108, 2015

2. Wotton D, Lo RS, Lee S and Massagué J: A Smad transcriptional corepressor. Cell 97: 29-39, 1999.

3. Bartholin L, Powers SE, Melhuish TA, Lasse S, Weinstein M and Wotton D: TGIF inhibits retinoid signaling. Mol Cell Biol 26: 990-1001, 2006.

4. Hamid R and Brandt SJ: Transforming growth-interacting factor (TGIF) regulates proliferation and differentiation of human myeloid leukemia cells. Mol Oncol 3: 451-463, 2009.

5. Willer A, Jakobsen JS, Ohlsson E, Rapin N, Waage J, Billing M, Bullinger L, Karlsson S and Porse BT: TGIF1 is a negative regulator of MLL-rearranged acute myeloid leukemia. Leukemia 29: 1018-1031, 2015.

6. Nakakuki K, Imoto I, Pimkhaokham A, Fukuda Y, Shimada Y, Imamura M, Amagasa T and Inazawa J: Novel targets for the 18p11.3 amplification frequently observed in esophageal squamous cell carcinomas. Carcinogenesis 23: 19-24, 2002. 
7. Hu ZL, Wen JF, Xiao DS, Zhen H and Fu CY: Effects of transforming growth interacting factor on biological behaviors of gastric carcinoma cells. World J Gastroenterol 11: 84-88, 2005.

8. Liu ZM, Tseng HY, Tsai HW, Su FC and Huang HS: Transforming growth factor $\beta$-interacting factor-induced malignant progression of hepatocellular carcinoma cells depends on superoxide production from Nox4. Free Radic Biol Med 84: 54-64, 2015.

9. Wang Y, Wang H, Gao H, Xu B, Zhai W, Li J and Zhang C: Elevated expression of TGIF is involved in lung carcinogenesis. Tumour Biol 36: 9223-9231, 2015.

10. Xiang G, Yi Y, Weiwei H and Weiming W: TGIF1 promoted the growth and migration of cancer cells in nonsmall cell lung cancer. Tumour Biol 36: 9303-9310, 2015.

11. Yeh BW, Wu WJ, Li WM, Li CC, Huang CN, Kang WY, Liu ZM and Huang HS: Overexpression of TG-interacting factor is associated with worse prognosis in upper urinary tract urothelial carcinoma. Am J Pathol 181: 1044-1055, 2012.

12. Huang HS, Liu ZM, Chen PC, Tseng HY and Yeh BW: TG-interacting factor-induced superoxide production from NADPH oxidase contributes to the migration/invasion of urothelial carcinoma. Free Radic Biol Med 53: 769-778, 2012.

13. Zhang MZ, Ferrigno O, Wang Z, Ohnishi M, Prunier C, Levy L, Razzaque M, Horne WC, Romero D, Tzivion G, et al: TGIF governs a feed-forward network that empowers Wnt signaling to drive mammary tumorigenesis. Cancer Cell 27: 547-560, 2015.

14. Kwon YJ, Leibovitch BA, Bansal N, Pereira L, Chung CY, Ariztia EV, Zelent A, Farias EF and Waxman S: Targeted interference of SIN3A-TGIF1 function by SID decoy treatment inhibits Wnt signaling and invasion in triple negative breast cancer cells. Oncotarget 8: 88421-88436, 2017.

15. Wang Y, Pan T, Wang H, Li L, Li J, Zhang C and Yang $\mathrm{H}$ Silencing of TGIF attenuates the tumorigenicity of A549 cells in vitro and in vivo. Tumour Biol 37: 12725-12730, 2016.

16. Wang Y, Zhai W, Wang H, Xia X and Zhang C: Benzo(a)pyrene promotes A549 cell migration and invasion through up-regulating Twist. Arch Toxicol 89: 451-458, 2015.

17. Zhang Z, Liu X, Feng B, Liu N, Wu Q, Han Y, Nie Y, Wu K, Shi Y and Fan D: STIM1, a direct target of microRNA-185, promotes tumor metastasis and is associated with poor prognosis in colorectal cancer. Oncogene 34: 4808-4820, 2015.

18. Glondu M, Liaudet-Coopman E, Derocq D, Platet N, Rochefort H and Garcia M: Down-regulation of cathepsin-D expression by antisense gene transfer inhibits tumor growth and experimental lung metastasis of human breast cancer cells. Oncogene 21: 5127-5134, 2002 .

19. Hui L, Zhang S, Dong X, Tian D, Cui Z and Qiu X: Prognostic significance of twist and N-cadherin expression in NSCLC. PLoS One 8: e62171, 2013

20. Lu X, Yan C, Huang Y, Shi D, Fu Z, Qiu J and Yin Y: Mouse double minute 2 (MDM2) upregulates Snail expression and induces epithelial-to-mesenchymal transition in breast cancer cells in vitro and in vivo. Oncotarget 7: 37177-37191, 2016.

21. Castillo LF, Tascón R, Lago Huvelle MR, Novack G, Llorens MC, Dos Santos AF, Shortrede J, Cabanillas AM, Bal de Kier Joffé E, Labriola L, et al: Glypican-3 induces a mesenchymal to epithelial transition in human breast cancer cells. Oncotarget 7 : 60133-60154, 2016.

22. De P, Carlson JH, Wu H, Marcus A, Leyland-Jones B and Dey N: Wnt-beta-catenin pathway signals metastasis-associated tumor cell phenotypes in triple negative breast cancers. Oncotarget 7 : 43124-43149, 2016.

23. Byun HJ, Darvin P, Kang DY, Sp N, Joung YH, Park JH, Kim SJ and Yang YM: Silibinin downregulates MMP2 expression via Jak2/STAT3 pathway and inhibits the migration and invasive potential in MDA-MB-231 cells. Oncol Rep 37: 3270-3278, 2017

24. Xu X, Yan Q, Wang Y and Dong X: NTN4 is associated with breast cancer metastasis via regulation of EMT-related biomarkers. Oncol Rep 37: 449-457, 2017.

25. Min KW, Kim DH, Do SI, Kim K, Lee HJ, Chae SW, Sohn JH Pyo JS, Oh YH, Kim WS, et al: Expression patterns of stromal MMP-2 and tumoural MMP-2 and -9 are significant prognostic factors in invasive ductal carcinoma of the breast. APMIS 122: 1196-1206, 2014

26. Kim D and Rhee S: Matrix metalloproteinase-2 regulates MDA-MB-231 breast cancer cell invasion induced by active mammalian diaphanous-related formin 1. Mol Med Rep 14: 277-282, 2016.
27. Sullu Y, Demirag GG, Yildirim A, Karagoz F and Kandemir B: Matrix metalloproteinase-2 (MMP-2) and MMP-9 expression in invasive ductal carcinoma of the breast. Pathol Res Pract 207: 747-753, 2011.

28. Zheng L, Zhang YM, Zhan YZ and Liu CX: Momordica cochinchinensis seed extracts suppress migration and invasion of human breast cancer ZR-75-30 cells via down-regulating MMP-2 and MMP-9. Asian Pac J Cancer Prev 15: 1105-1110, 2014.

29. Chen Y, Wang X, Chen G, Dong $C$ and Zhang D: The impact of matrix metalloproteinase 2 on prognosis and clinicopathology of breast cancer patients: A systematic meta-analysis. PLoS One 10: $\mathrm{e} 0121404,2015$.

30. Pei S, Yang X, Wang H, Zhang H, Zhou B, Zhang D and Lin D: Plantamajoside, a potential anti-tumor herbal medicine inhibits breast cancer growth and pulmonary metastasis by decreasing the activity of matrix metalloproteinase-9 and -2 . BMC Cancer 15 : 965,2015

31. Ni X, Xia T, Zhao Y, Zhou W, Wu N, Liu X, Ding Q, Zha X, Sha J and Wang S: Downregulation of miR-106b induced breast cancer cell invasion and motility in association with overexpression of matrix metalloproteinase 2. Cancer Sci 105: 18-25, 2014.

32. Zhang YF, Yu Y, Song WZ, Zhang RM, Jin S, Bai JW, Kang HB, Wang $X$ and Cao XC: miR-410-3p suppresses breast cancer progression by targeting Snail. Oncol Rep 36: 480-486, 2016.

33. Ma SY, Park JH, Jung H, Ha SM, Kim Y, Park DH, Lee DH, Lee S, Chu IH, Jung SY, et al: Snail maintains metastatic potential, cancer stem-like properties, and chemoresistance in mesenchymal mouse breast cancer TUBO-P2J cells. Oncol Rep 38: 1867-1876, 2017.

34. Moody SE, Perez D, Pan TC, Sarkisian CJ, Portocarrero CP, Sterner CJ, Notorfrancesco KL, Cardiff RD and Chodosh LA: The transcriptional repressor Snail promotes mammary tumor recurrence. Cancer Cell 8: 197-209, 2005.

35. Geradts J, de Herreros AG, Su Z, Burchette J, Broadwater G and Bachelder RE: Nuclear Snaill and nuclear ZEB1 protein expression in invasive and intraductal human breast carcinomas. Hum Pathol 42: 1125-1131, 2011.

36. Tran DD, Corsa CA, Biswas H, Aft RL and Longmore GD Temporal and spatial cooperation of Snaill and Twist1 during epithelial-mesenchymal transition predicts for human breast cancer recurrence. Mol Cancer Res 9: 1644-1657, 2011.

37. Zhang K, Corsa CA, Ponik SM, Prior JL, Piwnica-Worms D, Eliceiri KW, Keely PJ and Longmore GD: The collagen receptor discoidin domain receptor 2 stabilizes SNAIL1 to facilitate breast cancer metastasis. Nat Cell Biol 15: 677-687, 2013.

38. Tran HD, Luitel K, Kim M, Zhang K, Longmore GD and Tran DD: Transient SNAIL1 expression is necessary for metastatic competence in breast cancer. Cancer Res 74: 6330-6340, 2014.

39. Dey N, Barwick BG, Moreno CS, Ordanic-Kodani M, Chen Z, Oprea-Ilies G, Tang W, Catzavelos C, Kerstann KF, Sledge GW Jr, et al: Wnt signaling in triple negative breast cancer is associated with metastasis. BMC Cancer 13: 537, 2013.

40. Tan Z, Zheng H, Liu X, Zhang W, Zhu J, Wu G, Cao L, Song J, Wu S, Song L, et al: MicroRNA-1229 overexpression promotes cell proliferation and tumorigenicity and activates $\mathrm{Wnt} / \beta$-catenin signaling in breast cancer. Oncotarget 7: 24076-24087, 2016.

41. Yin L, Gao Y, Zhang X, Wang J, Ding D, Zhang Y, Zhang J and Chen H: Niclosamide sensitizes triple-negative breast cancer cells to ionizing radiation in association with the inhibition of Wnt//3-catenin signaling. Oncotarget 7: 42126-42138, 2016.

42. Li S, Li S, Sun Y and Li L: The expression of $\beta$-catenin in different subtypes of breast cancer and its clinical significance. Tumour Biol 35: 7693-7698, 2014.

43. Lin SY, Xia W, Wang JC, Kwong KY, Spohn B, Wen Y, Pestell RG and Hung MC: Beta-catenin, a novel prognostic marker for breast cancer: Its roles in cyclin D1 expression and cancer progression. Proc Natl Acad Sci USA 97: 4262-4266, 2000.

44. Khramtsov AI, Khramtsova GF, Tretiakova M, Huo D, Olopade OI and Goss KH: Wnt/beta-catenin pathway activation is enriched in basal-like breast cancers and predicts poor outcome. Am J Pathol 176: 2911-2920, 2010.

45. Xu J, Prosperi JR, Choudhury N, Olopade OI and Goss KH: $\beta$-catenin is required for the tumorigenic behavior of triplenegative breast cancer cells. PLoS One 10: e0117097, 2015. 